\title{
Patates'te Hassas Damla Sulama Programlarının Yapılmasında Toprak Nem Sensörlerinin Kullanılması
}

\author{
Ali İbrahim AKIN1* \\ Levent Abdullah ÜNLENEN² \\ 'Atom Enerjisi Kurumu, Sarayköy Nükleer Araștırma ve Eğitim Merkezi, Ankara \\ ${ }^{2}$ Gıda Tarım ve Hayvancılık Bakanlığı, Patates Araștırma Enstitüsü Müdürlüğü, Niğde
}

*Sorumlu yazar e-posta (Corresponding author e-mail): ali.akin@taek.gov.tr

DOI: 10.21657/topraksu.338301

Öz

Sulama suyunun etkin bir șekilde kullanılması farklı bilgileri gerektirmektedir. Etkin bir sulama programının yapılmasında toprağın su durumunun izlenmesi bitki sulamasında hedeflerimize ulașmayı sağlar. Çalıșmada farklı toprak nem ölçüm cihazları, siltli tınlı toprakta, hassas sulama programı yapıımasında test edilmișlerdir. Nötron problar, frekans domain problar, tansiyometreler ve granüler matrix sensörler birbirleriyle mukayese edilmiștir. Granüler matrix sensörlerin okunması, otomatik olarak datatoplayıcılar ve manuel olarak elde tașınır okuyucu ile yapılmıștır. Uygulamalar sonucunda toprak nem sensörlerinin bitki yetiștirme ve toprak suyu muhafazasında kullanılması faydalı bulunmuș ve tavsiye edilmektedir.

Anahtar Kelimeler: Cevaplanabilirlik, gözenekli seramik, sulama programı, toprak nem sensörü, toprak suyu.

\section{Precise Irrigation Scheduling on Drip Irrigated Potato Using Soil Moisture Sensors}

\begin{abstract}
The efficient use of irrigation water requires several kinds of information. One element of an efficient irrigation scheduling is monitoring the soil to assure that the crop irrigation goals are being met. Various soil moisture measuring devices were tested for irrigation scheduling in silt loam. Neutron probes, frequency domain probes, tensiometers, and granular matrix sensors were compared. Granular matrix sensors were tested as read automatically by a datalogger and read manually with a hand-held meter. Practical suggestions are provided to use soil moisture sensors to the benefit of crop production and water conservation.
\end{abstract}

Key words: Responsiveness, porous ceramic, irrigation scheduling, soil moisture sensor, soil water.

\section{GíRiș}

Hassas sulama programlarının yapılması, pazar değeri yüksek ürünlerin değerini yükseltmesinin yanında suyun muhafazası ile beraber yüzeysuları ve taban sularının kalite özelliklerini korumaktadır.

Sulama programlarında bir toprak nem sensörünün kullanılması, topraktaki su ve toprakta suyun tutulma potansiyeli ile ilgili zamanında ve hassas bilgilerin alınmasını kolayca sağlar. Sensörler, bitki ve toprak özellikleri açısından özel olmalıdır. Pazarlanabilir ürün ve kalitesi açısından önem

arzeden toprak suyundaki değișim miktarlarını hızlı ve gerçeğe yakın olarak ölçebilmelidir. Sensör okumalarının, sulama planlamalarında anlamlı ve yardımcı olması için, așırı sık veya yoğun sulamalardan kaçınılması gerekir. Oregon Ovası Treasure Vadisinin tipik topraklarında hassas sulama planlaması yapmak amacıyla çeșitli toprak nem sensör tipleri ölçüm ve kullanıșllığı açısından test edilmiștir. Tansiyometreler ve granülar matrix sensörler ile toprak su potansiyeli, nötron prob ve 
frekans domain sensörler ile hacimsel toprak su miktarları ölçülmüștür. Bir denemede de, gözenekli seramik kapların kullanması test edilmiștir.

\section{MATERYAL VE YÖNTEM}

Sensörlerin karșılaștırma çalıșması ABD'deki Oregon Devlet Üniversitesi'nin Ontario' daki Malheur Deneme ístasyonu'nda damla sulamayla sulanan patates deneme tarlasında yapılmıștır. 26 Nisan 2002 tarihinde "Mazama" çeșidi patates tohumları sıra arası $90 \mathrm{~cm}$ ve sıra üzeri $22,5 \mathrm{~cm}$ olacak șekilde ekilmiștir. Toprak bünyesi siltli tın olup, $\mathrm{pH}^{\prime} \mathrm{s}$ 8.1 ve organik madde oranı ise $\% 2^{\prime}$ dir. Damlatıcı borular (T-tipi, uluslararası T-sistemleri, San Diego, CA) iki patates sıra arasına ve yüzeyden $10 \mathrm{~cm}$ derinliğe serilmiștir. Damlatıcı aralığı $30 \mathrm{~cm}$ olup, 30 m'de akıș oranı 0.8 I dak ${ }^{-1}$ dır. Sulama günlük olarak ve bir önceki günün evapotranspirasyon değerine göre yapılmıșdır. Patates evapotranspirasyon (Etc) değerleri AgriMet hava istasyonu tarafindan Malheur Deneme İstasyonu'ndan toplanan verileri kullanarakmodifiyePenman denklemi (Wright 1982) ile hesaplanmıștır.15 Temmuz'dan 25 Temmuz'a kadar ve yine 30 Temmuz'dan 7 Ağustos'a kadar, hem ıslak ve hem de kuru nem koșulları altında sensör performanslarını değerlendirmek amacıyla bitkiler sulanmamıștır.

Sensörler, Haziran ayı ortasında deneme sahasında bir patates sırası boyunca yerleștirilmiștir. Altı çeșit sensör damlatıcı boru ile patates sıraları arasına, damlatıcı borulardan $20 \mathrm{~cm}$ ve patates sıralarından 25 cm uzağa monte edilmiștir. Sensörler yüzeyden $23 \mathrm{~cm}$ derinliğe yerleștirildi. Deneme tesadüf blokları deneme desenine göre dört tekerrürlü olarak kurulmuștur.

Test edilen sensörler :

- Aquaflex sensör (Streat Instruments, Christchurch, New Zealand),

- Watermark sensör (Watermark Soil Moisture Sensors model 200SS; Irrometer Co., Riverside, CA) okumaları otomatik olarak her 8 saatte bir AM400 Soil Moisture Data Logger (M.K. Hansen Co., East Wenatchee, WA) ile yapıImıș,

- Watermark sensör okumaları manuel olarak 30 KTCD-NL meter (Irrometer Co.) ile yapılmıș,

- Tansiyometre (Moisture Indicator, Irrometer Co., Riverside, (A),

- Gro Point (Environmental Sensors Inc., Escondido, CA),
- Moisture Point (Environmental Sensors Inc., Escondido, CA) ,

- Nötron Prob model 503 DR hydroprobe (Boart Longyear, Martinez, CA).

Tansiyometre ve Watermark sensörler ile toprak su potansiyeli ölçülmüștür. Toprak su potansiyeli ölçümlerinden önce Watermark sensörler kalibre edilmiștir (Shock vd., 1998). Diğer sensörler ise hacimsel olarak toprak su miktarını ölçmek için kullanılmıștır. Tansiyometre ve Watermark sensörler toprak burgusu yardımıyla $20 \mathrm{~cm}$ derinliğe yerleștirilmiștir. Tansiyometrelerin okunan su sütunu değerleri -60 ile $-70 \mathrm{kPa}$ arasında olduğu zaman düzenli sıfırlama gerekmektedir. Gro point sensörü kompakt ve toprağa gömülmesi kolaydır. Nötron prob ile okumaların alınabilmesi için tüm lokasyonlarda access tüpler (PVC) uygun yerlere ve uygun derinliklere yerleștirilmiștir. Moisture point prob, üretici șirket tarafından sağlanan bir metal çubuk yardımı ile $90 \mathrm{~cm}$ derinliğe yerleștirilmiș ve herbir lokasyonda okumalar alınmıștır. Aquaflex sensörü ise $3 \mathrm{~m}$ uzunluğunda düz bir șerittir. İki adet Aquaflex sensörü, Aquaflex 2 kanallı datalogger'a (Streat Instruments) bağlanmıștır. Nötron prob ve Moisture point prob ile tüm lokasyonlarda farklı derinliklerde toprak nemi ölçülmüștür.

Nötron prob ile çalıșırken, özellikle o toprağa ait kalibrasyon eğrisine intiyaç vardır. Kalibrasyonda; sensörlerin yerleștirilmeleri sırasında dört tekerrürden bozulmamıș toprak örnekleri alınmıș, hemen nem kaplarına konularak tartılmıș ve $100^{\circ} \mathrm{C}^{\prime}$ de 48 saat süreyle kurutulduktan sonra tekrar tartılmıștır. Toprak örneklerinde gravimetrik metod ile hacimsel olarak toprak suyu miktarları

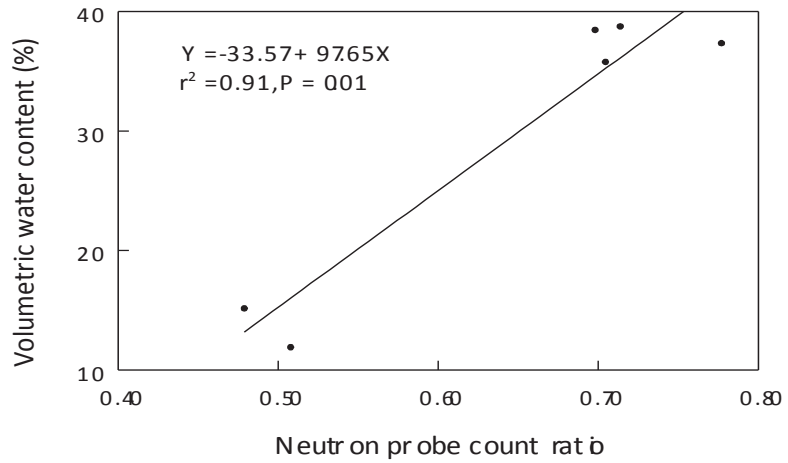

Sekil 1. Gravimetrik olarak belirlenen toprak nem miktarı ile nötron prob sayım oranları arasındaki kalibrasyon eğrisi

Figure 1. Calibration of the neutron probe to volumetric soil water content. Malheur Experiment Station, Oregon State University, Ontario, Oregon, 2002. 
hesaplanmıștır. Toprak örneklerinin alındığı yerlerden aynı zamanda access tüplerde nötron okumaları yapıımıștır. Nötron okumaları 32 sn'de yapıımıș ve standart için dört okuma alınmıștır. Nötron okumalarının standart okumaya oranları (sayım oranı) ile alınan toprak örneklerinde tespit edilen hacimsel toprak suyu miktarları regresyona tabi tutularak, nötron okuma değerlerini hacimsel su miktarına çeviren; $Y=-33,6+97,7 X$ eșitliği bulunmuștur. Eșitlikte $X$ değeri sayım oranını, $Y$ ise \% hacimsel toprak suyu miktarını vermektedir. Nötron prob kalibrasyon eğrisinin determinasyon katsayısı $r^{2}$ değeri $0.91(p=0,01)$ dir (Șekil 1).

\section{BULGULAR VE TARTIȘMA}

Tansiyometre, Watermark sensör ve nötron prob ile deneme süresince toprağın yaș ve kuru dönemlerine ait ölçümler alınmıștır (Șekil 2). Gro Point sensör ile ölçümler alınmıș, fakat nem ölçüm aralığı nötron proba oranla dar bulunmuștur. Diğer sensörlerle mukayese

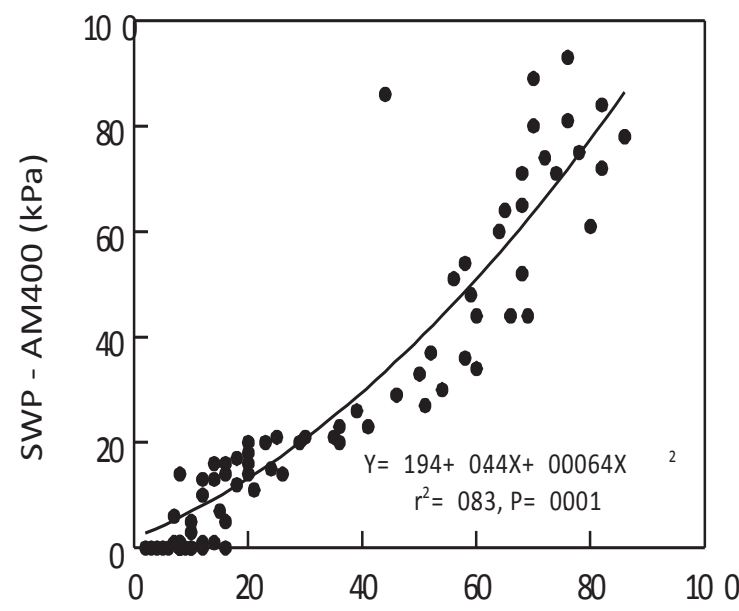

SWP -T ensi ometer ( $\mathrm{kPa})$

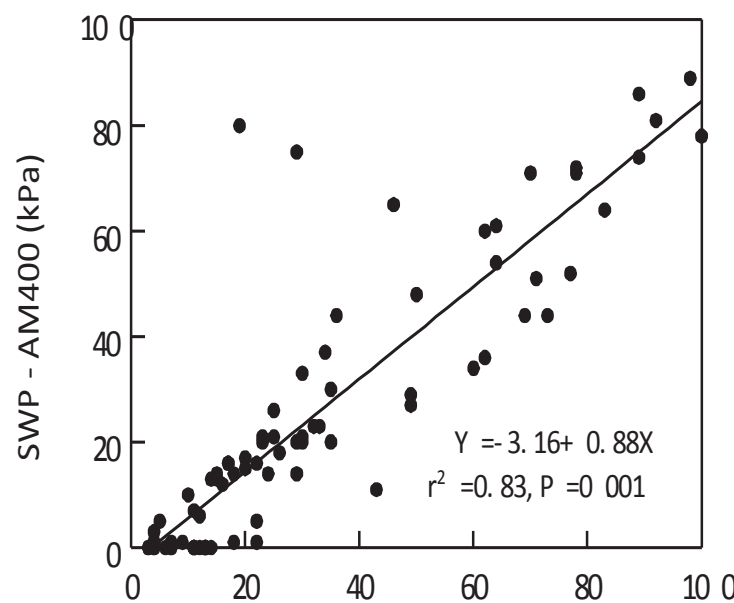

SWP -3 0 KTळ me e r( kPa)
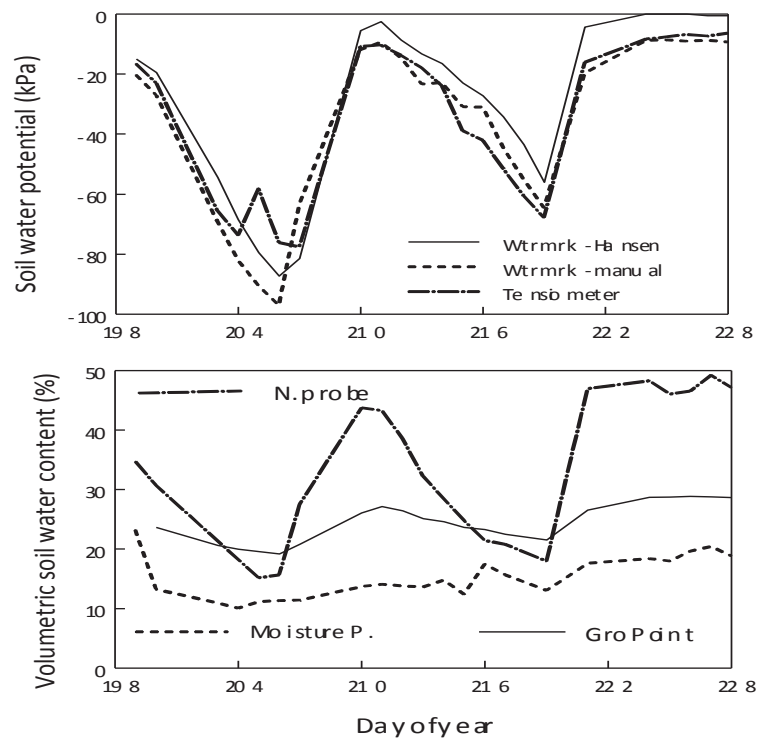

Șekil 2. Beș ayrı sensöre ait deneme süresince okunan toprak nem değerleri. Malheur Experiment Station, Oregon State University, Ontario, Oregon, 2002.

Figure 2. Soil moisture over time for five types of soil moisture sensor.

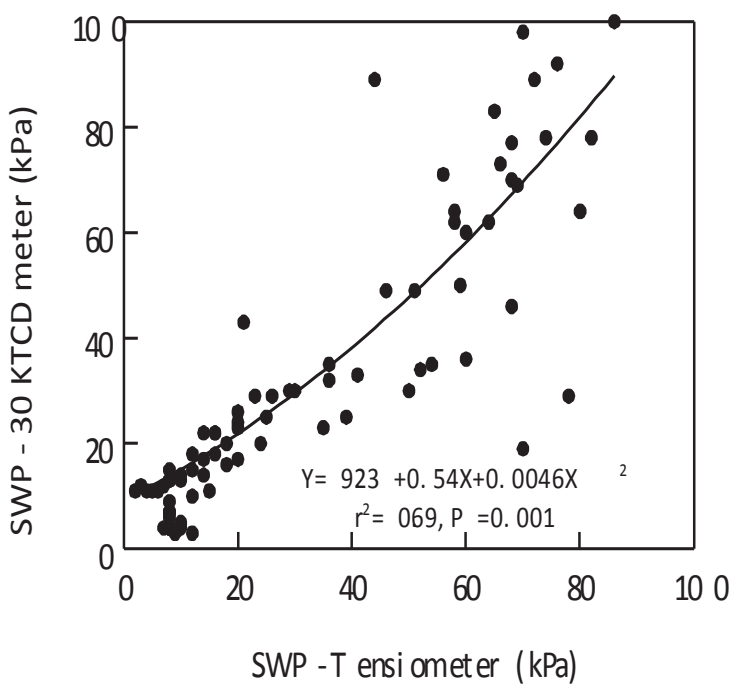

Șekil 3. Farklı sensörler ile ölçülen toprak su potansiyeli (SWP) değerleri arasındaki ilișki. Nokta değerleri dört sensörün ortalamasıdır.

Figure 3. Regressions of soil water potential (SWP) measured by three instruments. Malheur Experiment Station, Oregon State University, Ontario, Oregon, 2002. 

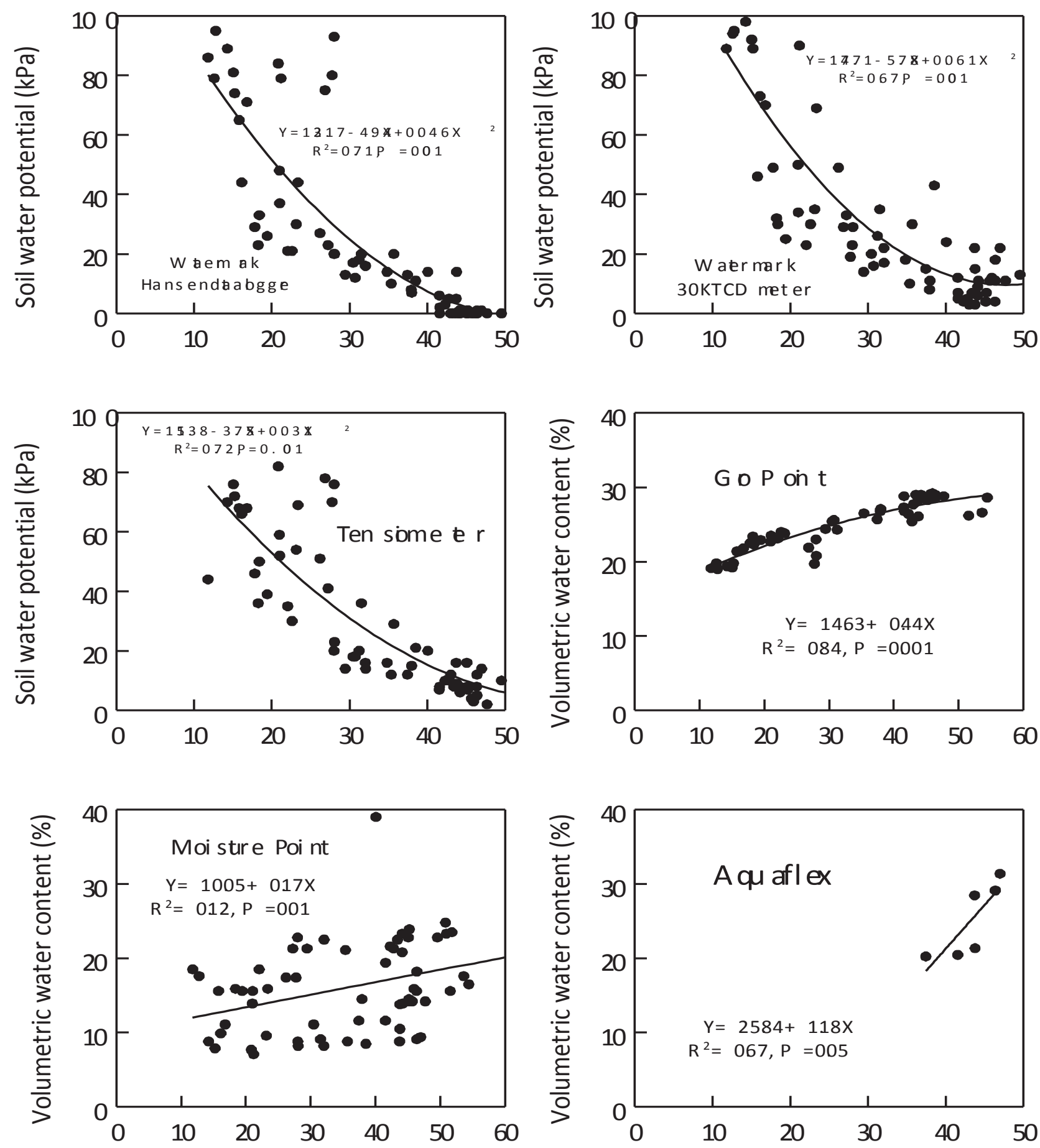

Vo L metric waterco nten $t(\%)$

Vo $\mathrm{l}$ metri waterco nten $\mathrm{t}(\%)$

Șekil 4. Nötron prob ile ölçülen hacimsel nem değerleri (X ekseninde) ile altı farklı toprak nem sensörü ile ölçülen toprak nem değerleri (Y ekseninde) arasındaki ilișki.

Figure 4. Volumetric soil water content measured by a neutron probe ( $X$ axis) regressed against soil moisture data (Y axis) measured by 6 types of soil moisture sensor. Malheur Experiment Station, Oregon State University, Ontario, Oregon, 2002.

edildiğinde, Moisture Point sensörün toprağın yas ve kuru dönemlerine ait ölçümlerde, en az hassas olduğu bulunmuștur. Tespit edilemeyen nedenlerden ötürü, Aquaflex datalogger ile sadece üç gün data toplanmıș, dolayısıyla bu döneme ait grafik verilememiștir. 
Watermark sensörlere ait; AM400 datalogger ve 30 KTCD metre okumalarıyla, tansiyometre okumaları arasında ilișki bulunmuștur (Șekil 3). Ayrıca, AM400 datalogger ile 30 KTCD metre okumaları arasında da ilișki bulunmuș olup, aynı eșitlik kullanılarak; her iki alet ile okunan elektriksel iletkenlik değerleriyle toprak su potansiyeli hesaplanabilmektedir (Shock vd., 20011

Moisture Point sensör haricindeki diğer bütün sensörler ile nötron prob arasında $\left(r^{2}>0,6\right)$ ilișki bulunmuștur (Șekil 4). Aquaflex ve Gro Point sensörler ile ölçülen toprak nem okumaları, nötron prob'la ölçülen nem okumalarına oranla düșük bulunmuștur (Șekil 4). Moisture Point ile toprak nem okuma değerleri, nötron prob, Aquaflex ve Gro Point sensörler ile okunan değerlere oranla oldukça düșük bulunmuștur.

\section{SONUÇLAR}

Tansiyometre, Watermark sensör ve nötron prob ile deneme süresince toprağın yas ve kuru dönemlerine ait ölçümler alınmıștır (Șekil 2). Gro Point sensör ile ölçümler alınmıș, fakat nem ölçüm aralığı nötron proba oranla dar bulunmuștur. Diğer sensörlerle mukayese edildiğinde, Moisture Point sensörün toprağın yaș ve kuru dönemlerine ait ölçümlerde, en az hassas olduğu bulunmuștur. Tespit edilemeyen nedenlerden ötürü, Aquaflex datalogger ile sadece üç gün data toplanmıș, dolayısıyla bu döneme ait grafik verilememiștir.
Watermark sensörlere ait; AM400 datalogger ve 30 KTCD metre okumalarıyla, tansiyometre okumaları arasında ilișki bulunmuștur (Șekil 3). Ayrıca, AM400 datalogger ile 30 KTCD metre okumaları arasında da ilișki bulunmuș olup, aynı eșitlik kullanılarak; her iki alet ile okunan elektriksel iletkenlik değerleriyle toprak su potansiyeli hesaplanabilmektedir (Shock vd., 2001).

Moisture Point sensör haricindeki diğer bütün sensörler ile nötron prob arasında $\left(r^{2}>0,6\right)$ ilișki bulunmuștur (Șekil 4). Aquaflex ve Gro Point sensörler ile ölçülen toprak nem okumaları, nötron prob’la ölçülen nem okumalarına oranla düșük bulunmuștur (Șekil 4). Moisture Point ile toprak nem okuma değerleri, nötron prob, Aquaflex ve Gro Point sensörler ile okunan değerlere oranla oldukça düșük bulunmuștur.

\section{KAYNAKLAR}

Shock C C, Barnum J M, Seddigh M (1998). Calibration of Watermark Soil Moisture sensors for irrigation management. p. 139-146 in Proceedings of the International Irrigation Show, Irrigation Association, San Diego, CA.

Shock C C, Corn A, Jaderholm S, Jensen L, Shock C A (2001). Evaluation of the AM400 soil moisture datalogger to aid irrigation scheduling. Irrigation Association, 2001 Proceedings of the International Irrigation Show, p 111-116.

Wright J L (1982). New evapotranspiration crop coefficients. J. Irrig. Drain. Div., ASCE 108:577. 